\title{
Procesamiento de imágenes digitales aplicado al análisis de color y textura del piloncillo de la Huasteca Potosina
}

\section{Digital image processing applied to piloncillo color and texture analysis of the Huasteca Potosina}

LÁRRAGA-ALTAMIRANO, Hugo*†, PIEDAD-RUBIO, Ana, HERNÁNDEZ-LÓPEZ, Dalia y GÓMEZ-RODRÍGUEZ, Ismael

Tecnológico Nacional de México - Instituto Tecnológico de Ciudad Valles, Carretera al Ingenio Plan de Ayala Km. 2, Colonia Vista Hermosa, C.P. 79010, Ciudad Valles, S.L.P.

ID $1^{\text {er }}$ Autor: Hugo, Lárraga-Altamirano / ORC ID: 0000-0001-8258-9418, Researcher ID Thomson: T-2296-2018, arXivAuthor ID: Hugo_Larraga, CVU CONACYT ID: 626539

ID $1^{\text {er }}$ Coautor: Ana, Piedad-Rubio / ORC ID: 0000-0003-1258-0383, Researcher ID Thomson: T-2477-2018, arXiv Author ID: ampiedad, CVU CONACYT ID: 732279

ID $2^{\text {do }}$ Coautor: Dalia, Hernández-López / ORC ID: 0000-0002-2751-5886, Researcher ID Thomson: T-2470-2018, arXivAuthor ID: DaliaHernandez, CVU CONACYT ID: 536472

ID $3^{\text {er }}$ Coautor: Ismael, Gómez-Rodríguez / ORC ID: 0000-0003-3667-9986, Researcher ID Thomson: T-2459-2018, arXivAuthor ID: ismaelgomezrdz, CVU CONACYT ID: 947957

DOI: $10.35429 / J T I P .2019 .6 .3 .7 .13$

Recibido 03 de Enero, 2019; Aceptado 09 Marzo, 2019

\section{Resumen}

El presente trabajo demuestra la implementación de técnicas de procesamiento de imágenes para analizar el color y la textura de productos agroindustriales, en este caso, del piloncillo o panela en su variedad granulado y de cono. Se desarrolló una herramienta tecnológica basada en software capaz de cuantificar el color y la textura para así, implementar controles de calidad que apoyen la comercialización de este producto hecho en la Huasteca Potosina hacia mercados globales. Se propone el uso de un método de clasificación no supervisada (clusterización) para definir el color o colores del piloncillo denominado K-means. Para el caso del análisis de textura se utilizan métodos estadísticos de segundo orden derivados de la matriz de coocurrencia y seis descriptores texturales de Haralick: contraste, homogeneidad, energía, ASM, correlación y disimilitud. El prototipo desarrollado fue validado en 24 comunidades productoras de piloncillo granulado y de cono, todas ellas pertenecientes a los municipios de Tanlajás y Tancanhuitz, S.L.P. Los resultados del análisis de color y textura han sido relacionados con los métodos de manufactura que se emplean actualmente para identificar mejoras que ayuden a la estandarización del proceso de producción.

Piloncillo, K-means, Haralick

\begin{abstract}
The present work demonstrates the implementation of image processing techniques to analyze the color and texture of agroindustrial products, in this case, of the piloncillo or panela in its granular and cone variety. A technological tool based on software was developed, capable of quantifying color and texture and thus implementing quality controls to support the commercialization of this product made in Huasteca Potosina towards global markets. An unsupervised classification method (clustering) is proposed to define the color or colors of the piloncillo, called K-means. In the case of texture analysis, second-order statistical methods derived from the co-occurrence matrix and six Haralick textural descriptors are used: contrast, homogeneity, energy, ASM, correlation and dissimilarity. The developed prototype was validated in 24 producing communities of granulated and cone-shaped piloncillo belonging to the municipalities of Tanlajas and Tancanhuitz, S.L.P. The results of the analysis of color and texture have been related to the manufacturing methods that are currently used, to identify improvements that help standardize the production process.
\end{abstract}

Piloncillo, K-means, Haralick

Citación: LÁRRAGA-ALTAMIRANO, Hugo, PIEDAD-RUBIO, Ana, HERNÁNDEZ-LÓPEZ, Dalia y GÓMEZRODRÍGUEZ, Ismael. Procesamiento de imágenes digitales aplicado al análisis de color y textura del piloncillo de la Huasteca Potosina. Revista de Tecnologías en Procesos Industriales. 2019. 3-6: 7-13

\footnotetext{
* Correspondencia del Autor (hugo.larraga@tecvalles.mx)

$\dagger$ Investigador contribuyendo como primer autor.
} 


\section{Introducción}

La caña de azúcar es el cultivo de mayor producción a nivel mundial, México ocupa el sexto lugar de entre los principales países productores de esta especie (FAO, 2019). La Huasteca Potosina, se distingue por ser una región cañera, razón principal que ha motivado el resurgimiento de industrias transformadoras de esta materia prima, tal es el caso de los productores de piloncillo. Denominado también panela o azúcar no centrifugada, el piloncillo busca colocarse en mercados globales como un edulcorante orgánico libre de procesos industriales que repercuten negativamente en la salud de los consumidores.

Sin embargo, su comercialización ofrece nuevos retos para la industria piloncillera relacionados con las prácticas de fabricación artesanales carentes de métodos estandarizados de producción, controles de calidad escasos o nulos, limitada aplicación de normas de inocuidad y la utilización de equipo y accesorios de acero inoxidable. Estos factores influyen en la calidad del producto principalmente en dos aspectos: la inocuidad y la presentación, específicamente del color y la textura (Cuevas, Baca, Borja, Grass, \& Rivera, 2017).

A medida que las industrias enfrentan la presión de la competencia global por colocar más y mejores productos al alcance de todos, el concepto de calidad va adquiriendo relevancia, tanto, que no es posible evadirla. Aun cuando no existe una regulación internacional que determine las condiciones sensoriales y físicoquímicas del piloncillo, es posible determinar el grado de calidad a través de características de aspecto como el color y la textura (la inocuidad no es abordada en este estudio) que, de acuerdo a la norma mexicana NMX-F-596-SCFI-2016 son especificaciones sensoriales del piloncillo, descritas como lo indica la Tabla 1 (DOF, 2016).

\begin{tabular}{|l|l|}
\hline Característica & \multicolumn{2}{|c|}{ Descripción } \\
\hline Aspecto & Uniforme \\
\hline Sabor & $\begin{array}{l}\text { Dulce, característico al jugo de caña } \\
\text { de azúcar }\end{array}$ \\
\hline Tonalidad & Café claro al oscuro \\
\hline Olor & Característico al jugo de caña \\
\hline
\end{tabular}

Tabla 7 Especificaciones sensoriales del piloncillo Fuente NMX-F-596-SCFI-2016
El presente proyecto focaliza su área de estudio en la construcción de una herramienta tecnológica basada en software que sea capaz de cuantificar el color y la textura del piloncillo por medio del procesamiento de imágenes digitales y con esto, generar parámetros que permitan ubicar el mercado destino del producto. Las fases para la construcción del sistema de información que enmarcan la metodología de desarrollo del proyecto son: adquisición de la imagen, considerando factores como la iluminación controlada y las cámaras digitales como sensores de captura; el preprocesamiento, en donde la imagen se transforma a diferentes espacios de color necesarios para la segmentación; por último, el análisis de color y textura para lo cual se propone el uso de un método de clasificación no supervisada (clusterización) para definir el color o colores del piloncillo denominado K-means y para el caso del análisis de textura se utilizan métodos estadísticos de segundo orden derivados de la matriz de coocurrencia y los descriptores texturales de Haralick.

\section{Materiales}

El escenario de iluminación controlada se construyó bajo las recomendaciones de la norma ISO 3664:2009 tomando como referencia las especificaciones de iluminación D50 para el color de la luz, la distribución de la misma y el fondo para controlar la reflexión especular (International Organization for Standardization, 2009). La cabina de luz consiste en una caja de madera de dimensiones $1.20 \times 70 \times 65$, el espacio permite ajustar la distancia entre la fuente lumínica y el objeto para determinar el nivel de iluminación (luxes) además, integra una lámpara led de $4500 \mathrm{~K}$ con una potencia de 980 lúmenes, tal como se muestra en la Figura 1

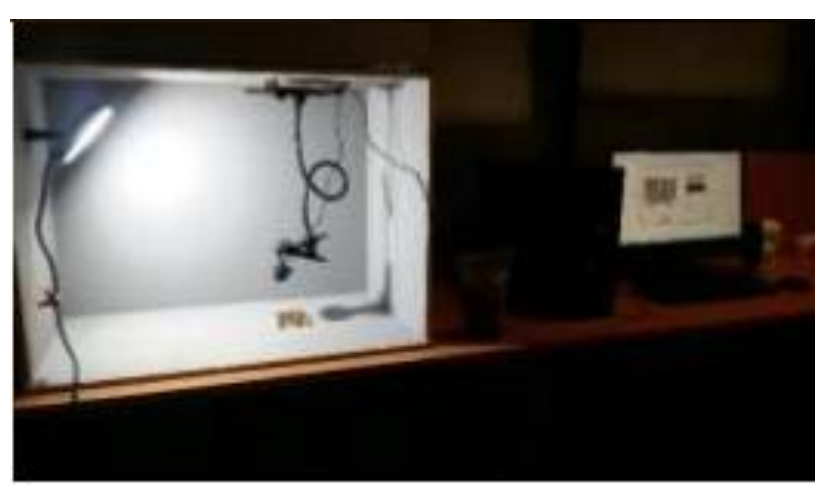

Figura 2 Caja de iluminación

Fuente original 
Para la adquisición de la imagen se utilizó una cámara USB, con calidad HD a 1080px con enfoque automático, la cual se posicionó en dirección al objeto a una distancia fija de 20 centímetros. El software requerido para el desarrollo del prototipo consistió en un Sistema Operativo Windows 10 y el lenguaje de programación Python en su versión 2.7 con las interfaces de programación para aplicaciones (API): OpenCV orientada al procesamiento de imágenes, Numpy y Scipy para el manejo matemático de vectores y matrices, entre otras (García Moya, 2016).

\section{Metodología}

\section{Adquisición de imagen}

Con el producto colocado en el set de iluminación controlada se adquiere la imagen en formato RGB (red-green-blue) mediante un módulo de software implementado para controlar la cámara digital. La dimensión de la imagen depende de la resolución del dispositivo de captura la cual es representada $\mathrm{N}$ x M x 3; siendo $\mathrm{N}$ el número de pixeles del alto de la imagen, $\mathrm{M}$ el ancho y los tres canales $\mathrm{R}, \mathrm{G}$ y B. La imagen es almacenada en memoria primaria para su transformación a una matriz de valores numéricos de tamaño $\mathrm{N}$ x 3 ; siendo $\mathrm{N}$ el número de pixeles totales de la imagen y las tres columnas representan cada canal del espacio de color.

\section{Preprocesamiento}

El objetivo de esta fase es la segmentación, en otras palabras, extraer únicamente el área de la imagen del piloncillo del resto de la fotografía. La imagen resultado de la segmentación es nombrada como área de interés, contiene la información requerida para el procesamiento de manera que, no intervienen otros datos que pudieran alterar los resultados finales (Palomino \& Román Concha, 2009). El modelo de segmentación propuesto para piloncillo granulado se describe a continuación:

1. La imagen de color se transforma a escala de grises, ya que es el sistema de color utilizado por el algoritmo de segmentación.

2. Se aplica el algoritmo de detección de bordes Canny para identificar los límites extremos del área de interés.
3. Se ubica el centro de la imagen para recortar el área de interés, considerando que la forma del contenedor es rectangular (Figura 2)

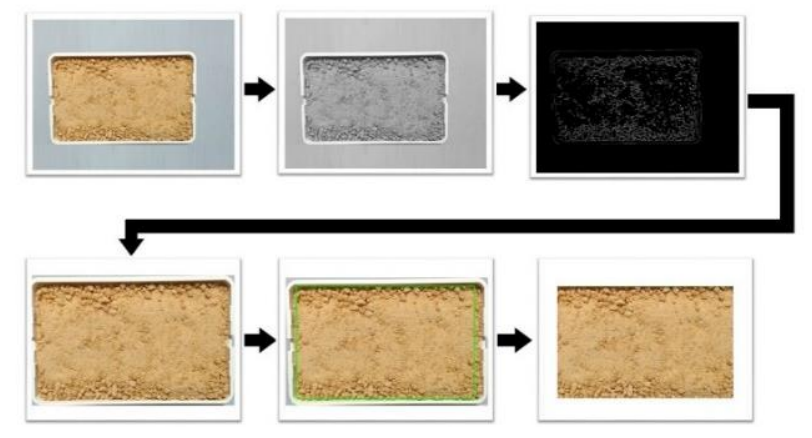

Figura 2 Modelo de segmentación de piloncillo granulado Fuente original

\section{Evaluación de color}

La matriz Nx3 resultante de la adquisición, es uno de los atributos de entrada para el proceso de cuantificación del color. El método propuesto consiste en la agrupación (clusterización) de los pixeles de la imagen por semejanza de color, el algoritmo usado se denomina k-means el cual calcula un centroide (con una notación en el espacio de color CIELAB) que representa el color del grupo de pixeles al que pertenece. De esta manera, es posible expresar el color del piloncillo mediante un número reducido de datos (Jung, Kang, \& Heo, 2014). La calibración de la función K-means, consiste en determinar el número óptimo de cluster (k), en otras palabras, la cantidad de colores que definirán al piloncillo. Para esto, es utilizado el método del Codo, con un rango de $\mathrm{k}=$ [ 5 a 20] en 40 sujetos de prueba. Los $40 \mathrm{k}$ óptimos derivados de la operación anterior se someten a estadísticas de primer orden para analizar el valor óptimo de bandas de color (A Syakur, 2018) (Figura 3).

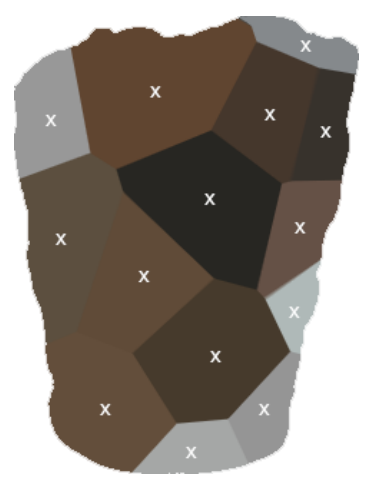

Figura 3 Esquema del proceso de clusterización Fuente original

LÁRRAGA-ALTAMIRANO, Hugo, PIEDAD-RUBIO, Ana, HERNÁNDEZ-LÓPEZ, Dalia y GÓMEZ-RODRÍGUEZ, Ismael. Procesamiento de imágenes digitales aplicado al análisis de color y textura del piloncillo de la Huasteca Potosina. Revista de Tecnologías en Procesos Industriales. 2019 


\section{Análisis de textura}

Propone caracterizar mediante descriptores de Haralick la textura del piloncillo granulado para determinar de una manera cuantificable que tan similares son dos productos en esta característica. Implementa un método estadístico de segundo orden denominado Matriz de Coocurrencia. Para el cálculo de la matriz, se consideran varios elementos como: el tamaño de la ventana, la distancia entre pixeles y la dirección de vecindad, los cuales se describen a continuación:

1. El tamaño de la ventana depende de la característica textural que se desea estudiar, con la restricción de ser cuadrada y con número impar de pixeles. Para el caso del piloncillo granulado una ventana móvil de 35 x 35 resulta conveniente pues es posible encontrar en esta área las características de textura que se analizan.

2. La distancia entre pixeles es 1 , el mínimo necesario para evitar saltos que ignoren información importante con una dirección de $0^{\circ}$ (derecha) (Presutti, 2004).

La ventana móvil recorre la imagen inspeccionando los detalles de textura, obteniendo una matriz de coocurrencia por cada desplazamiento y seis descriptores texturales (ASM, Contraste, Correlación, Homogeneidad, Disimilitud y Energía). Este proceso consume importante recurso de computo por lo que se recomienda hacer desplazamientos mayores a un pixel, por ejemplo, utilizar un sobreposicionamiento (overlaping) del 50\% del tamaño de la ventana. De tal manera, que de una sola imagen se obtendrá una matriz de datos de seis filas que representan los descriptores de Haralick y $\mathrm{N}$ columnas, el número de ventanas móviles que mapearon la imagen (Figura 4).

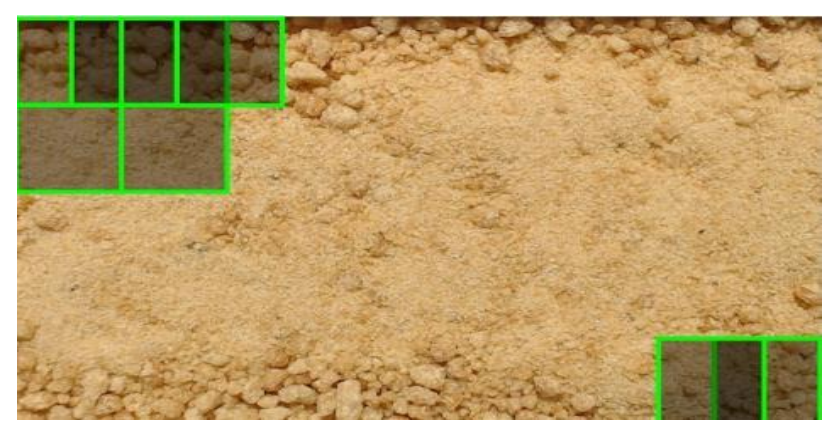

Figura 4 Modelo de ventana móvil con desplazamiento overlaping del $50 \%$

Fuente original
La selección del descriptor de textura que caracteriza con mayor eficacia el piloncillo granulado presenta variabilidad, para lo cual se crea una tabla de medidas estadísticas de primer orden: promedio, desviación estándar y varianza, este último dato permite deducir cual o cuales descriptores describen la textura. La información estadística generada se emplea para determinar el Coeficiente de Pearson con el que se infiere si existen relación entre dos o más descriptores.

\section{Resultados}

El prototipo de software desarrollado integra un módulo para la adquisición de la imagen, una interfaz intuitiva que controla el flujo de video obtenido por cámara digital para que el usuario capture el piloncillo que ha sido colocado dentro de la caja de iluminación (Figura 5).

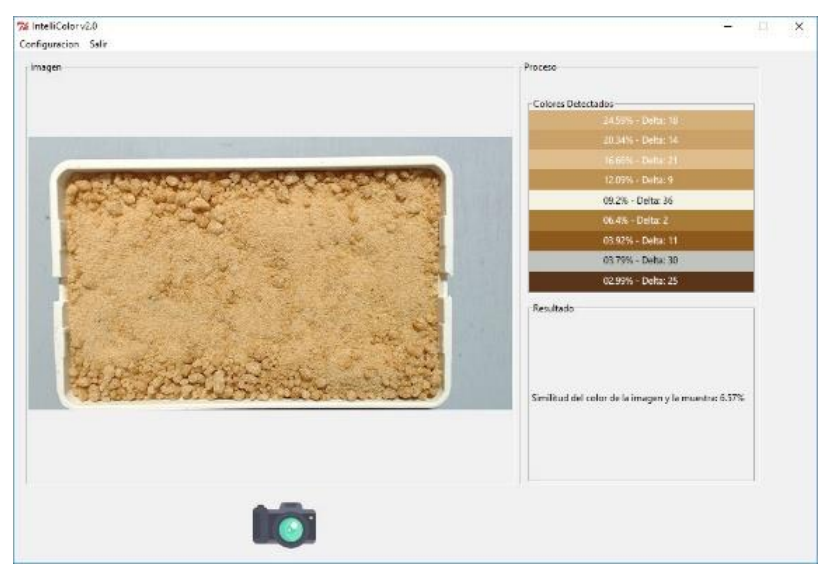

Figura 5 Módulo de adquisición de imagen Fuente original

La tarea de segmentar resulta un proceso complejo con un costo computacional alto, por la gran cantidad de operaciones a nivel de pixel que se realizan; operaciones morfológicas, operadores de umbralización y detección de bordes, entre otros.

Para eliminar el contorno del contenedor de la muestra, se obtiene el pixel central de la imagen y se realiza un recorte omitiendo los cuatro bordes que contienen datos innecesarios, como el material del contenedor y gránulos del producto formados por la acción de vaciado. Aún cuando la imagen ha sido recortada, se cuenta con una porción suficiente que capta todos los detalles de color y textura que se buscan (Figura 6). 


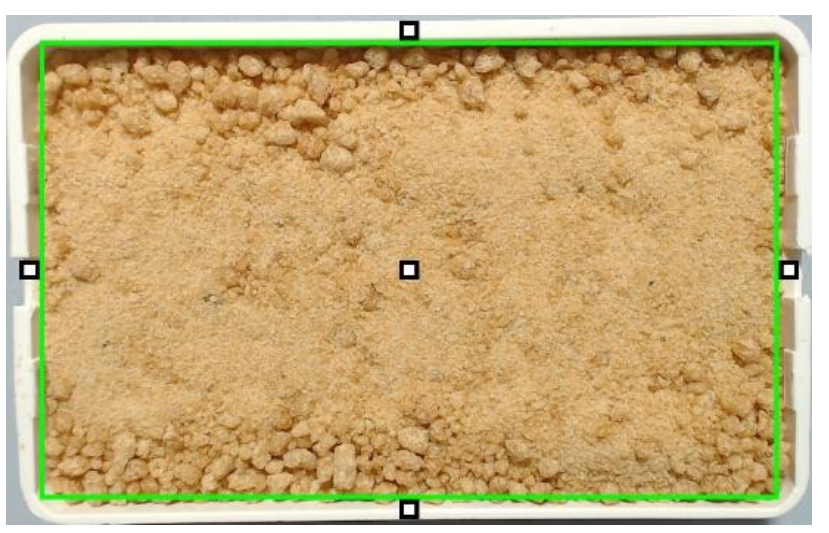

Figura 6 Extracción del área de interés Fuente Original

El proceso de clusterización para la evaluación del color inicia con la calibración del k-means. Aunque no es parte del núcleo del prototipo, se generó un script adicional para determinar el número de clúster suficiente que definan los colores del piloncillo. La prueba de calibración se efectuó con el método del Codo en 40 imágenes con un rango de $\mathrm{k}$ de 1 a 20 clúster (Figura 7).

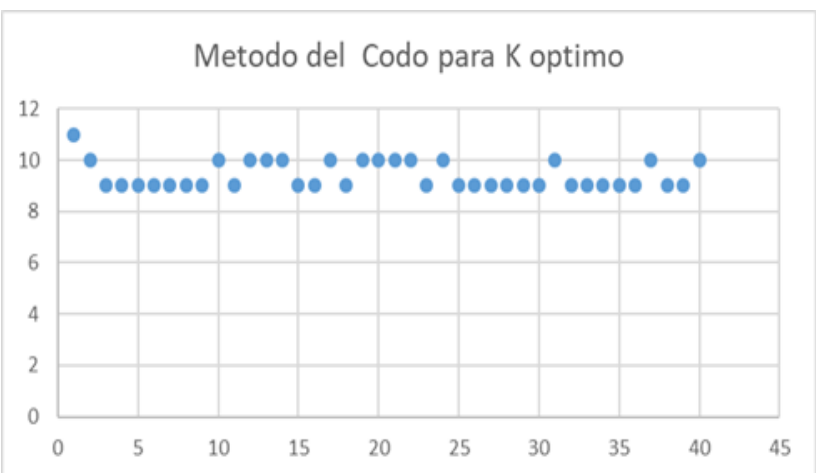

Figura 7 Resultados del método del Codo con 40 imágenes muestra

Fuente Original

La tabla 2 muestra las estadísticas de primer orden generadas del grupo de datos para identificar el valor óptimo, el cual es nueve $(\mathrm{k}=9)$.

\begin{tabular}{|l|l|}
\hline Medida Estadística & Valor \\
\hline Media & 9.4 \\
\hline Mediana & 9 \\
\hline Moda & 9 \\
\hline Varianza & 0.297435897 \\
\hline Desviación estándar & 0.54537684 \\
\hline
\end{tabular}

Tabla 2 Estadísticas primer orden de los resultados del método del Codo Fuente Original
El prototipo integra un módulo de comparación de colores con base en el cálculo del factor Delta E del CIE 2000, la intención primera es identificar diferencias de color entre la muestra procesada y un patrón de color ideal. La interpretación del escalar Delta E se basa en las recomendaciones de la norma ISO 12647 para evaluar diferencias de color bajo, etiquetando como colores no similares los valores mayores de cinco.

Posterior a la calibración y las pruebas iniciales se obtuvieron muestras de piloncillo granulado producidas en comunidades de Tanlajás y Tancanhuitz, municipios de la Huasteca Potosina. Se cuenta con 78 productos que han sido procesadas extrayendo tres muestras en recipientes separados de cada uno para determinar el abanico colorimétrico del piloncillo en esas regiones. Para ejemplificar los resultados, la Tabla 3 muestra la definición de colores del piloncillo granulado de solo un grupo de productores, cabe hacer mención que los colores muestran similitud aceptable entre ellos según el Delta.

\begin{tabular}{|c|c|c|c|c|c|}
\hline \multicolumn{3}{|c|}{ Lab } & Delta & Color & Comunidad \\
\hline 74.33 & 6.47 & 31.61 & 0 & & Xilatzen \\
\hline 72.43 & 6.28 & 31.13 & 1.430468 & & Xilatzen \\
\hline 71.94 & 7.23 & 33.16 & 1.935898 & & Barrancón \\
\hline 76.28 & 6.53 & 36.9 & 2.577985 & & \\
\hline 74.35 & 3.75 & 26.21 & 2.915588 & & El Fortín \\
\hline 77.85 & 4.26 & 30.56 & 3.078144 & & El ojo \\
\hline 76.23 & 7.7 & 39.99 & 3.50262 & & \\
\hline 71.71 & 3.58 & 25.75 & 3.710192 & & Null \\
\hline 68.81 & 5.14 & 31.52 & 4.323122 & & El May \\
\hline 68.65 & 2.99 & 29.08 & 5.1654 & & El Fortín \\
\hline 67.88 & 4.62 & 28.06 & 5.278192 & & El Fortín \\
\hline 68.27 & 8.76 & 38.87 & 5.475763 & & Barrancón \\
\hline 67.04 & 5.56 & 32.35 & 5.65936 & & San José de Xilatzen \\
\hline 67.28 & 3.59 & 28.84 & 5.91219 & & \\
\hline
\end{tabular}

Tabla 3 Resultados parciales de evaluación de color Fuente Original

El análisis de textura es la siguiente fase del procesamiento, el primer paso es determinar cuál o cuáles descriptores texturales de los seis propuestos caracterizan con mayor objetividad al piloncillo granulado. Para la experimentación se toman las mismas imágenes de entrada que la cuantificación del color, es decir, 78 sujetos de prueba en escala de grises. La matriz de coocurrencia utiliza una ventana móvil de 35 x 35 pixeles, la cual se desplaza de manera horizontal y vertical a lo largo de la matriz de grises, poniendo especial atención cuando la ventana se acerca a los límites de la misma para no procesar pixeles que no pertenecen al cuerpo del granulado. 
Cada desplazamiento de la ventana ocurre a una distancia de $\mathrm{N} / 2+1$, siendo $\mathrm{N}$ el tamaño de la ventana, así, se reduce el número de matrices de coocurrencia que se crean, y por lo tanto, se optimiza el procesamiento de los descriptores texturales sin sacrificar veracidad en los resultados. Lo anterior da como resultado 78 matrices de $6 \times \mathrm{M}$, siendo $\mathrm{M}$ el número de ventanas móviles utilizadas para recorrer la superficie de la imagen. Cada columna es promediada para tener un valor representativo de cada descriptor textural obteniendo solo una matriz de 78 × 6 misma que es utilizada para realizar un análisis de varianza e identificar el descriptor de Haralick que caracteriza con mayor eficiencia a la textura del piloncillo (Figura 8).

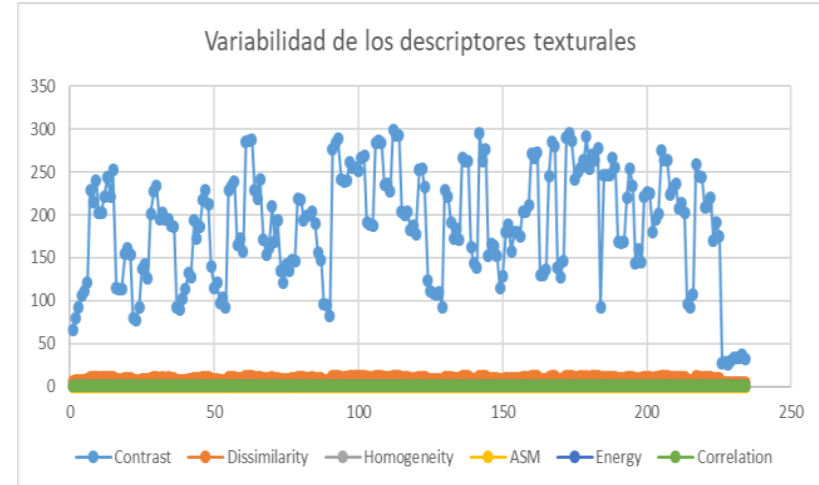

Figura 8 Análisis de varianza descriptores de Haralick Fuente original

Otro dato de interés es conocer que descriptor textural pudiera guardar relación con los dos identificados, de manera que, sean considerados como características adicionales en el estudio de la textura. Para esto, se construye una matriz de coeficientes de Pearson como se observa en la Tabla 4, en la cual se reafirma que el contraste y la disimilitud guardan estrecha relación uno respecto al otro.

\begin{tabular}{|l|r|r|r|}
\hline & \multicolumn{1}{|c}{ Contrast } & \multicolumn{1}{c|}{ Dissimilarity } & Homogeneity \\
\hline Contrast & 1 & 0.980039096 & -0.878430866 \\
\hline Dissimilarity & 0.980039096 & 1 & -0.954248219 \\
\hline Homogeneity & -0.878430866 & -0.954248219 & 1 \\
\hline ASM & -0.939543273 & -0.96764368 & 0.93941466 \\
\hline Energy & -0.955429839 & -0.973777554 & 0.930521593 \\
\hline Correlation & -0.140740612 & -0.309376404 & 0.527730933 \\
\hline
\end{tabular}

\begin{tabular}{|c|c|c|c|}
\hline & ASM & Energy & Correlation \\
\hline Contrast & -0.939543273 & -0.95542984 & -0.14074061 \\
\hline Dissimilarity & -0.96764368 & -0.97377755 & -0.3093764 \\
\hline Homogeneity & 0.93941466 & 0.93052159 & 0.52773093 \\
\hline $\mathrm{ASM}$ & 1 & 0.99807974 & 0.24224488 \\
\hline Energy & 0.998079742 & 1 & 0.20744173 \\
\hline Correlation & 0.242244878 & 0.20744173 & 1 \\
\hline
\end{tabular}

Tabla 4 Coeficiente de Pearson entre descriptores Haralick

Fuente original.

\section{Discusión}

Las fases de adquisición de la imagen y segmentación, proponen soluciones al problema de control de la iluminación acertadas desde el punto de vista de lo que se pretende cuantificar es la magnitud del color, no su reproducción fidedigna.

La Figura 7 muestra la dispersión de los niveles óptimos de $\mathrm{k}$ para la calibración de la función K-means, se aprecia que los números de clúster de inicio pueden descartarse para que no afecten las estadísticas de primer orden y se mantenga la normalización del conjunto, por esa razón se propone que el método del codo considere $\mathrm{k}=5$ como punto de partida. El algoritmo K-means de la librería sklearn de Python demuestra mayor estabilidad en el cálculo de los centroides de tal manera que la misma imagen obtiene valores sin varianza durante cada procesamiento elevando la confiabilidad de los resultados.

La diferencia de color Delta E sugiere un parámetro para clasificar los piloncillos dependiendo de las necesidades de cada productor, en otras palabras, si hay diferencia de color de una muestra respecto al patrón el productor puede tomar decisiones de comercialización hacia otros mercados o bien, considerar una inspección en su método de manufactura.

En el análisis de textura los elementos que presentan mayor varianza y, por lo tanto, son los descriptores que pueden caracterizar con más información la textura del piloncillo granulado son: el contraste y la disimilitud. El contraste refleja la variación del gris entre el pixel pivote y su vecino, se observa que en la textura granulada este valor es sumamente alto, podría inferirse que las texturas suaves o lisas proporcionarían valores bajos.

Parecida al contraste, la disimilitud muestra la disparidad que existe en los valores de intensidad entre los vecinos, a mayor valor mayor diferencia. Los descriptores texturales a excepción de la correlación mantienen relación entre ellos, algunos positiva, otros una correlación negativa debido a su origen de cálculo; sin embargo, la relación más fuerte sigue siendo entre el contraste y la disimilitud. 


\section{Agradecimiento}

Se agradece al Tecnológico Nacional de México por financiar el proyecto "Implementación de método estadístico basado en matriz de coocurrencia para análisis de textura en productos edulcorantes (azúcar no centrifugada)" a través de la convocatoria Apoyo a la Investigación Científica y Tecnológica en los Programas Educativos de los Institutos Tecnológicos Federales, Descentralizados y Centros 2018-2.

De la misma manera, se agradece a la sociedad productora de piloncillo Tze! Jkom Tzi! Maxtalab S.P.R. de R.L. y el Consejo Regional de Productores de Piloncillo Tzaplab Tenek S.P.R. de R.L. que brindaron las facilidades para la realización de este estudio.

\section{Conclusiones}

La evaluación del color pareciera ser trabajo de dispositivos sofisticados como lo son los colorímetros, sin embargo, el procesamiento de imágenes ha demostrado ser una herramienta útil en la industria alimentaria.

Para el caso particular de este estudio sin duda el software desarrollado permitió determinar el color y hacer comparaciones entre dos muestras para definir el porcentaje de similitud, cuidando desde luego que el escenario de captura conserve sus características técnicas en todo momento mientras las imágenes son obtenidas.

La clusterización de pixeles a través del k-means, permitió definir en k clusters (bandas de color) el cuerpo del piloncillo granulado, para determinar el número de grupos de pixeles optimo se ha utilizado el método del codo (Elbow). La diferencia entre dos muestras de color en el espacio CIE Lab se realiza con la fórmula CIEDE2000.

Los descriptores texturales de Haralick que mejor discriminan las características de textura del piloncillo granulado son: el contraste y la disimilitud. A través de estos valores es posible comparar la textura de una muestra respecto a otra para evaluar su calidad. La implementación de estos algoritmos en un programa de cómputo le permite actuar como un software de inspección de calidad, midiendo los rasgos de color y textura que son demandados bajo especificaciones estrictas en mercados de mayor competitividad.

\section{Referencias}

A Syakur, M. \&. (2018). Integration K-Means Clustering Method and Elbow Method For Identification of The Best Customer Profile Cluster. IOP Conference Series: Materials Science and Engineering.

Cuevas, R. V., Baca, d. M., Borja, B. M., Grass, R. J., \& Rivera, M. G. (2017). Agricultura familiar y tecnología para la. Revista Electrónica Nova Scientia. Obtenido de Agricultura familiar y tecnología para la elaboración de piloncillo granulado en la comunidad de Aldzulup Poytzén.

DOF. (2016). Piloncillo 100\% d ejugo de caña de azúcar (Sccharum officinarum). Especificaciones y métodos de prueba. México: Diario Oficial de la Federacíon.

FAO. (2019). FAOSTAT. Obtenido de Organización de las Naciones Unidas para la Alimentación y la Agricultura: http://www.fao.org/faostat/es/\#data/QC

García Moya, R. (2016). Machine Learning (en Python), con ejemplos.

International Organization for Standardization. (2009). ISO 3664:2009(E) Graphic technology and photography - Viewing conditions. Switzerland: ISO.

Jung, Y. G., Kang, M. S., \& Heo, J. (2014). Clustering performance comparison using $\mathrm{K}$ means and expectation maximization algorithms.

Palomino, N. L., \& Román Concha, U. (2009). Técnicas de Segmentación en Procesamiento Digital de. Facultad de Ingeniería de Sistemas e Informática.

Presutti, M. (2004). La matriz de co-ocurrencia en la clasificación multiespectral: tutorial para la enseñanza de medidas texturales en cursos de grado universitario. $4^{\text {a }}$ Jornada de Educação em Sensoriamento Remoto no Âmbito do Mercosul. 